\title{
Biological properties of African swine fever virus Odintsovo $02 / 14$ isolate and its genome analysis
}

\author{
Elsukova A.A. ${ }^{1}$, Shevchenko I.V. ${ }^{2}$, Varentsova A.A. ${ }^{3}$, Puzankova O.S. ${ }^{4}$, Zhukov I.Y. ${ }^{5}$, \\ Pershin A.S. ${ }^{6}$, Remyga S.G. ${ }^{7}$, Zinyakov N.G. ${ }^{8}$, Mazloum A. ${ }^{9}$, Vlasov I.N. ${ }^{10}$, \\ Igolkin A.S. ${ }^{11}$, Lozovoy D.A. ${ }^{12}$, Gruzdev K.N. ${ }^{13}$, Vlasova N.N. ${ }^{14}$ \\ ${ }^{1-9,11-14}$ FGBI "Federal Centre for Animal Health" (FGBI “ARRIAH”), 600901 Yur'evets, Vladimir, Russia. \\ ${ }^{10}$ Rosgenediagnostics, 141400, Rabochaya str., house 2A apt. 1, Himki (town), Moscow region, Russia.
}

\begin{abstract}
We performed analysis of the biological properties of African swine fever virus (ASF) isolate Odintsovo 02/14. Domestic pigs were inoculated with 50 (low) or 5000 (high) hemadsorbing doses (HAD) of the virus via intranasal (IN) or intramuscular (IM) routes, to investigate the pathogenesis of ASF virus Odintsovo 02/14 isolate. Our results indicated that filtered 10\% spleen suspension of ASFV isolate Odintsovo 02/14 induced an acute disease in pigs, resulting in 100\% mortality rate. For cultural viral suspension (3rd passage), produced in a PBM cells mortality rate was $85.7 \%$.

We also present an analysis of the complete genome of African swine fever virus (ASF) Odintsovo 02/14 isolate. It is 189333 nucleotide long and contains more than 160 open reading frames (ORFs). Complete nucleotide sequence of the genome of Odintsovo 02/14 isolate was obtained using pyrosequencing method and used to determine differences between the nucleotide sequences in the genomes of Odintsovo 02/14 and Georgia 01/2007. The genome of ASF virus Odintsovo 02/14 contains substitutions, insertions and deletions in genes encoding structural, membrane, and regulatory proteins, DNA reparation enzymes, host immune response evasion proteins, and MGF genes.
\end{abstract}

The intergenic region I73R/I329L of Odintsovo 02/14 isolate contains 10-nucleotide long tandem repeat sequence, missing in Georgia 01/2007.

Keywords-African swine fever (ASF), experimental challenge, complete genome sequencing, intergenic region, tandem repeats.

\section{INTRODUCTION}

In 2007 ASFV was detected in the Caucasus region, first in Georgia and subsequently in Armenia, Azerbaijan, and many regions of Russia, including regions that border other countries in Europe and Asia. Epizootiological, pathogenic and immunogenic characteristics of the virus, as well as lack of an effective vaccine make ASFV a global threat to pig industry. According to the sequencing of PCR products and the hemadsorption inhibition reaction, this pathogen has been assigned to II genotype and seroimmunotype VIII [3, 33].

Russian isolates of ASFV induce an acute form of the disease, characterized by hemorrhagic syndrome and multisystem damage, high level of viremia and $100 \%$ mortality in domestic pigs.

The unique morphology of ASFV causes its high persistence and longevity in environment.

The causative agent of ASF is a large DNA-containing enveloped virus with a virion $~ 200 \mathrm{~nm}$ in diameter. [13]. ASFV virus belongings to the Asfarviridae family. Its particles consist of a nucleoprotein core $\sim 80 \mathrm{~nm}$ in diameter. The genome containing electron-dense nucleoid enclosed in a lipid membrane and covered by an icosahedral capsid, made of 1892-2172 capsomeres. The virus acquires an external envelope during the budding process, thus forming extracellular virions about $\sim 200 \mathrm{~nm}$ in diameter $[2,19]$.

Viral dsDNA is 170-193 kbp long, and it contains 150-167 ORFs. Generally, changes in the genome length are the result of variation in the number of tandem repeats within a certain gene or intergenic region [1,27].

ASFV isolate Georgia 2007/1 has a genome of 189344 bp and contains 166 ORFs. Chapman D. et al. demonstrated the maximum homology of Georgia 2007/1 isolate and Mkuzi 1979 isolate by phylogenetic analysis of the nucleotide sequences of 125 ORFs. In addition, they revealed some differences in the grouping of genes, which may be a result of recombination occurring during the evolution of virus [9]. 
High variability in groups of genes responsible for the virulence expression and interaction with the host requires constant monitoring of changes in a viral genome [19]. Comparison of the genomes of ASFV isolates of varying virulence can help in determining virulence responsible genes and develop a strategy for making an effective vaccine.

The first complete genome sequence for ASFV was obtained by Yanez et al. in 1995 for Ba71V strain, adapted to Vero cells [31]. Recently, sequences from strains of different genotypes became available for comparative analyses [9, 10, 12].

Currently, next generation sequencing (NGS) is the best method for viral genome studying. A single NGS procedure allows determining the entire nucleotide sequence even for large viruses, like Poxviruses, ASF, Herpes, etc. [24]. It is a key tool for detection of variable and marker regions in a genome, which are required for epidemiological studies and analysis of the distribution of viral subpopulations [30]. It also allows sequencing of nucleotides at the ends of the viral genome, which cannot be determined using methods based on PCR products sequencing analysis [32].

Comparison of genomic changes and changes in the biological properties of the ASFV will allow us to find out sources of the genome variability; to determine the hallmarks for differentiating isolates by pathogenicity; to track the evolution stages of the ASFV and to identify possible pathogen introduction sources.

Therefore, the purpose of this study was analysis of the biological properties of Odintsovo 02/14 isolate and its complete genome sequencing.

\section{MATERIALS AND METHODS}

\subsection{Virus and cells}

Virus was isolated from the spleen of a wild boar, shot in Tarakanovskiy forestry, Odintsovo district, Moscow region. Primary porcine alveolar macrophages (PAM) cell-culture [18] was used for the isolation of virus from the original field samples (10\% filtered spleen suspension). Later, Odintsovo 02/14 virus was replicated in porcine bone marrow cells (PBM) for three consecutive passages $[11,18]$.

Cell cultures were infected with 0.1 HAD per cell. Examination of cultural properties was performed in primary porcine alveolar macrophages (PAM) and primary porcine kidney (PK). Alveolar macrophages from the lungs of healthy outbreed pigs were obtained by broncho-alveolar lavage with phosphate-buffered saline (PBS).

Two or three days old sub confluent monolayer cells were infected with the virus. First, cells were washed twice with maintenance medium MEM (Minimum Essential Media) containing 1\% antibiotics and anti-fungal, then inoculated with the filtered samples. After adsorption, (60 min at $37^{\circ} \mathrm{C}$ in $5 \% \mathrm{CO}_{2}$ ), DMEM (Dulbecco's Modified Eagle's Medium) supplied with $10 \%$ FBS (Fetal Bovine Serum) was added to cultural mattresses. The cell cultures were observed for the presence of hemadsorption.

\subsection{Virus titrations}

The titer of ASF virus was determined by hemadsorption in PBM. PBM cells were added to 96-well microtiter plates. Cells were inoculated at dilutions of 1:10. Growth medium with $0.1 \%$ washed homologous red blood cells (RBCs) was added to each well. 10 folds diluted samples were added in quadruplicate to the plates and incubated for 6 days. The virus titer was calculated by the appearance of $50 \%$ of cells expressing hemadsorption as $\mathrm{HAD}_{50} / \mathrm{cm}^{3}$.

\subsection{Hemadsorption types and its analysis}

After three days of incubating the subconfluent monolayer of PBM, it was infected with a $0.1 \mathrm{HAD}_{50} /$ cell and incubated for 48-72 hours in order to detect hemadsorption. Then the culture was photographed (15-20 images per sample) using microscope magnification of 400x. For every infected cell we counted the number of RBC's attached to it. 100-200 cells were counted in the field of view disposed along the diagonals of the sample. To avoid errors in the assessment of the hemadsorption type caused by the variations of the properties of cell cultures, the experiment was repeated three times on different batches of PBM cells. Statistical analysis included arithmetic mean values, standard error of arithmetic, evaluation of the reliability of the mean values, and significance of differences were performed using standard programs [28].

\subsection{Animals}

For experimental challenge with ASFV Odintsovo 02/14 isolates, we used 22 seronegative large white pigs; 8 in the first experiment and 14 in the second experiment, weighing 20-25 kg, aged 45-60 days, obtained from herds free of viral agents 
in Vladimir region of Russia. Pigs were dewormed prior to arrival to our facility, and kept within the housing facilities for 7 days prior to the onset of the experiment for accommodation to the new environment.

This study was approved by the Institutional Animal Care and Use Committee (IACUC) of FGBI ARRIAH, and conducted in compliance with local and federal guidelines. For this particular study, we used the lowest numbers of pigs previously shown to permit detection of statistical significances among treatments considering welfare principles. This minimum number of pigs required per treatment group was verified by the statistician before starting the experiments.

\subsection{Direct inoculation studies}

To study the biological properties of ASF virus Odintsovo 02/14 isolate and analyze the homogeneity of its population, we performed three experiments.

In the first experiment, we used 8 pigs. 6 pigs were assigned to 3 groups (two pigs in each group) and infected with 10\% boar

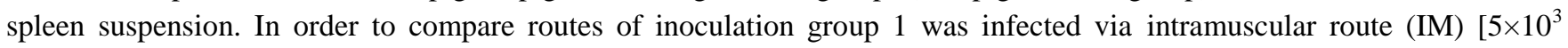
$\left.\mathrm{HAD}_{50}\right]$, groups 2 and 3 via intranasal (IN) $\left[5 \times 10 \mathrm{HAD}_{50}\right.$ and $5 \times 10^{3} \mathrm{HAD}_{50}$.] Two pigs were used for direct contact.

In the second experiment, we used virus from third passage PBM cell culture to infect the pigs. We used 14 animals, divided into 2 groups; in a first group 5 pigs were infected with $10 \mathrm{HAD}_{50}$ through IM route, and two pigs were used for direct contact. In the second group, 5 pigs were infected by $50 \mathrm{HAD}_{50}$ through IM route and 2 pigs were also used for direct contact.

In the third experiment, surviving animals from the previous experiment were infected with highly pathogenic ASFV isolate Boguchary 06/13 $\left[10^{3} \mathrm{HAD}_{50}\right]$.

IM infection was carried out by introducing $2 \mathrm{~cm}^{3}$ of virus-containing material in the right cucullaris muscle. Pigs assigned to IN inoculation were placed in sternal recumbency and inoculated with $2 \mathrm{~cm}^{3}$ of virus suspension (1 ml per nostril). After inoculation of pigs we conducted daily temperature registration and observations. We investigated the level of viremia, virus presence in nasal and fecal swabs and duration of illness prior to animal death. Determination of the level of viremia in infected pigs was evaluated by DIF and PCR.

\subsection{Direct contact (DC) transmission studies}

This experiment was performed to characterize ASFV transmission from inoculated pigs and viral dynamics in pigs challenged by direct contact. Healthy contact pigs were initially housed in separate rooms. Infected pigs were inoculated using the intranasal (IN) method as described. Upon detection of pyrexia (rectal temperature $\geq 40^{\circ} \mathrm{C}$ ) in infected animals $(5-6$ DPI), contact pigs were transferred and housed with infected pigs.

\subsection{Clinical evaluation and sample collection}

The clinical assessment and rectal temperature monitoring were conducted daily. Sample collection (whole blood with EDTA, clotted blood for serum collection and swab samples from the nasal cavity and anus) were performed every two days. Blood were collected from the cranial cava vein. Nasal and anal swabs were collected using sterile cotton swabs. Following collection, swabs were immediately immersed in $1 \mathrm{ml}$ of DMEM containing 5\% antibiotics and antifungals; then all samples were stored in microtubes at $-70^{\circ} \mathrm{C}$ until they were analyzed by virus isolation (VI) or PCR. Autopsy was performed on pigs as soon as possible following euthanasia or natural death. Tissues collected included: lung, thymus, liver, spleen, kidneys, and lymph nodes including: retropharyngeal, submandibular, gastrohepatic, renal and inguinal. Urine was also collected by direct aspiration from the urinary bladder at the time of necropsy. Collected tissue samples were placed in microtubes and stored at $-70^{\circ} \mathrm{C}$.

\subsection{Direct Immunofluorescence reaction}

For the direct immunofluorescence (DIF) anti-p72 monoclonal antibodies - FITC (Ingenasa, Spain) was used. Fluorescence observations were performed using Olympus fluorescence microscope (Japan) at 400x magnification.

\subsection{PCR}

Viral DNA was extracted directly from suspensions of clinical samples using the DNA-Sorb DNA Purification Kit "Interlabservice" (Russia) following the manufacturer's protocol. Real-time polymerase chain reactions (RT-PCRs) were performed using the "ASF detection Kit" ("Interlabservice") as recommended by the manufacturer. 


\subsection{Virus and DNA purification}

Extracellular virus was purified by sucrose gradient ultracentrifugation as described by Black D.N. and Brown F. (1976) [5]. ASF virus's DNA was extracted using the phenol/chloroform method [29].

For the pyrosequencing we needed to extract DNA from ASF virus that was replicated and harvested in PAM cells. In brief, the virus-containing suspension was centrifuged at $3000 \mathrm{rpm}$ for $40 \mathrm{~min}$ at $4^{\circ} \mathrm{C}$. The clarified virus-containing suspension was introduced into a hermetically sealable centrifuge tubes and centrifuged for 1 hour at $25.000 \mathrm{rpm}$. The viral pellets were resuspended in a small volume (no more than $10 \mathrm{~cm}^{3}$ ) of PBS (pH 7.2-7.4). DNase I and RNase A (final concentration $50 \mu \mathrm{g} / \mathrm{cm}^{3}$ ) were added to the virus-containing suspension and this mixture was incubated for 0.5 hours at $37^{\circ} \mathrm{C}$. Then pronase E was added to a final concentration of $200 \mu \mathrm{g} / \mathrm{cm}^{3}$ and incubated for $6-12$ hours at $37^{\circ} \mathrm{C}$.

Further, virus-containing suspension was applied to a sucrose step gradient 25\%-35\%-50\% and centrifuged at 25,000 rpm for 1, 5 hours. Virus band located over 50\% sucrose cushion was collected in a minimal volume (1-2 ml) and used to extract the viral DNA, sample was diluted 3-4 times with $1 \times$ TE buffer. Viral DNA was extracted using the phenol-chloroform method by Enjuanes L. et al. [16].

Analysis of the sample purity and determining its concentration was performed spectrophotometrically, by measuring optical density (A) at wavelengths of 260 and 280. Integrity of DNA was checked by electrophoretic separation on an agarose gel.

\subsection{Pyrosequencing of ASFV genome}

To determine the complete nucleotide sequence of ASF virus we used pyrophosphate sequencing (454 Life Sciences) on automated sequencer GS Junior (Roche, Germany) according to the manufacturer's protocols. The fragmentation of genomic dsDNA was performed by nebulization with nitrogen using «GS Rapid Library Prep Nebulizers», «GS RL Buffers Kit» (Roche, Germany) kits following the manufacturer's instructions. Further complex molecular genetics operations for the preparation of the library and sequencing was performed using the following kits: «GS Rapid Library Rgt/Adaptors Kit», «GS Rapid Library MID Adaptors Kit», «GS Junior emPCR Reagents (Lib-L)», «GS Junior emPCR Bead Recovery Reagents», «GS Junior emPCR Oil \& Breaking Kit», «GS Junior Seq. Reagents and Enzymes», «GS Junior Sequencing Buffers», «GS Junior Packing Beads \& Supplement CB» (Roche, Germany) according to the manufacturer's instructions. For genome assembling we used GS De Novo Assembler and GS Reference Mapper (454 Life Sciences) software.

\subsection{Comparative analysis}

Detection of changes in viral genes was performed by comparative analysis of the full-genome sequence of Odintsovo 02/14 isolate and full-genome sequence of Georgia 2007/01 isolate (GenBank). Alignment of ASF virus genome sequences was performed using the ClustalW (http://www.clustal.org/clustal2/) method.

\subsection{Statistical analysis}

In this study we used STATGRAPHICS® Centurion XV, version 1.15.02 [28] for data processing. The statistical analysis was carried out using method of analysis of repeated variations [8].

\subsection{ELISA}

To detect the presence of specific antibodies in the serum of pigs ELISA was carried out using Ingenasa commercial kit (Spain) according to the manufacturer's instructions.

\subsection{DNA electrophoresis}

DNA fragmentation was evaluated by electrophoretic separation in $0.7 \%$ agarose gel.

\section{RESUlTS}

\subsection{Cultural properties.}

To evaluate properties of Odintsovo 02/14 isolate in PAM culture, we chose the following parameters: hemabsorption presence and type, time and titer of viral accumulation (Table 1). 


\section{TABLE 1}

CULTURAL PROPERTIES OF ASF VIRUS ODINTSOVO 02/14 ISOLATE ON PAM

\begin{tabular}{|c|c|c|c|c|}
\hline \multirow{2}{*}{ Isolate } & Passage & $\begin{array}{c}\text { Number of RBC } \\
\text { attached to the } \\
\text { infected cell }\end{array}$ & $\begin{array}{c}\text { Virus accumulation } \\
\text { titer } \\
\left(\mathbf{l g} \mathbf{H A D}_{\mathbf{5 0}} / \mathbf{c m}^{\mathbf{3}}\right)\end{array}$ & $\begin{array}{c}\text { Virus } \\
\text { accumulation } \\
\text { time }(\mathbf{d a y s})\end{array}$ \\
\hline \multirow{3}{*}{ Odintsovo 02/14 } & 1 & $>50$ & $5,21 \pm 0,36$ & 7 \\
\cline { 2 - 5 } & 2 & $30-50$ & $6,66 \pm 0,14$ & 6 \\
\cline { 2 - 5 }
\end{tabular}

The titer of the third passage increased from 5.21 to $7.02 \mathrm{lg} \mathrm{HAD}_{50} / \mathrm{cm}^{3}$, while the accumulation time decreased from 7 to 5 days.

Furthermore, throughout the course of serial passaging we detected changes in hemadsorption type. In the first passage, $50 \%$ of infected cells were adherent to 30-50 erythrocytes, $25 \%$ of infected cells adhered to less than 30 erythrocytes, and $25 \%$ of infected cells to more than 50 erythrocytes, while in the third passage, $50 \%$ of infected cells adhered to less than 30 erythrocytes, $35 \%$ of infected cells were adherent to $30-50$ erythrocytes and $15 \%$ had adhesion with 50 erythrocytes (Figure $1)$.
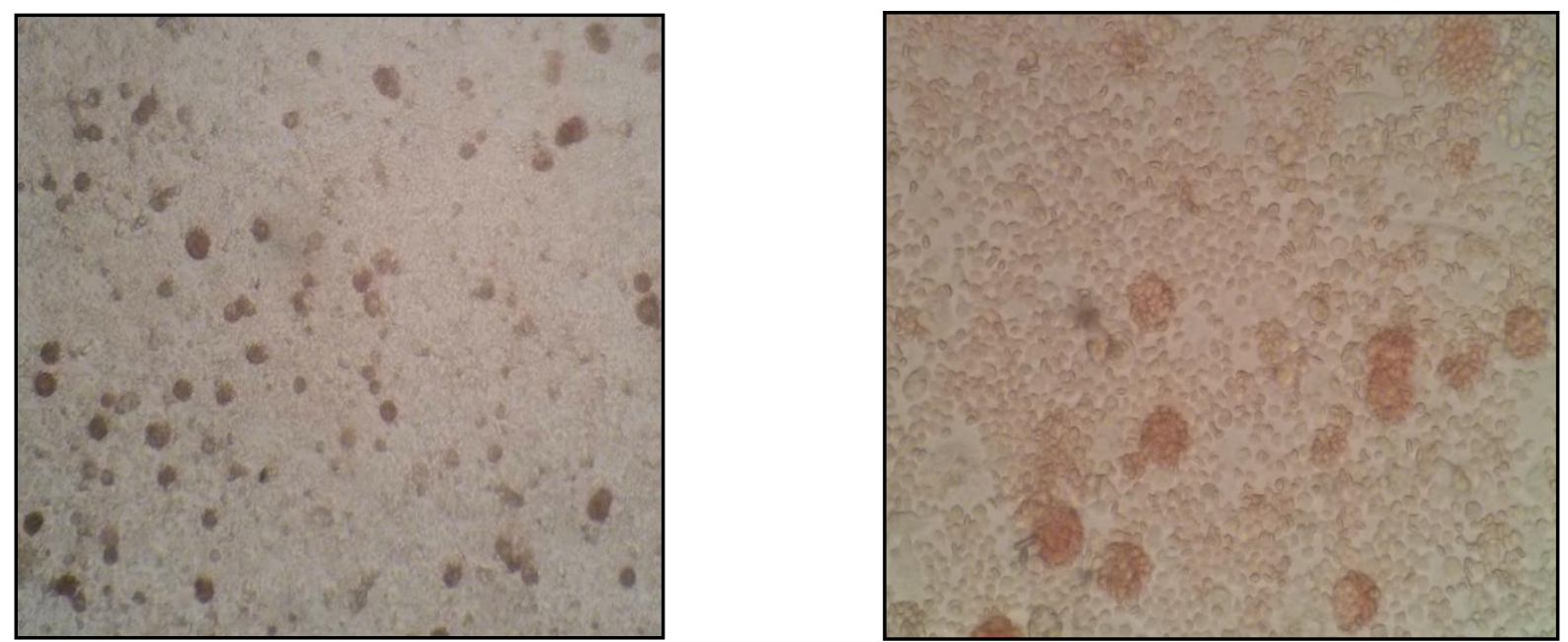

FIGURE 1 - HEMADSORPTION IN PAM CELL CULTURE INFECTED WITH ASF VIRUS ODINTSOVO 02/14 ISOLATE (left - magnification at 200x, right - magnification at 400x).

In primary cell culture PK, reproduction properties of Odintsovo 02/14 isolate were analyzed using $10 \%$ filtered spleen suspension $\left(5,21 \pm 0,36 \mathrm{lg} \mathrm{HAD}_{50} / \mathrm{cm}^{3}\right)$. Cell cultures were infected with $0.1 \mathrm{HAD}$ per cell (Figure 2).
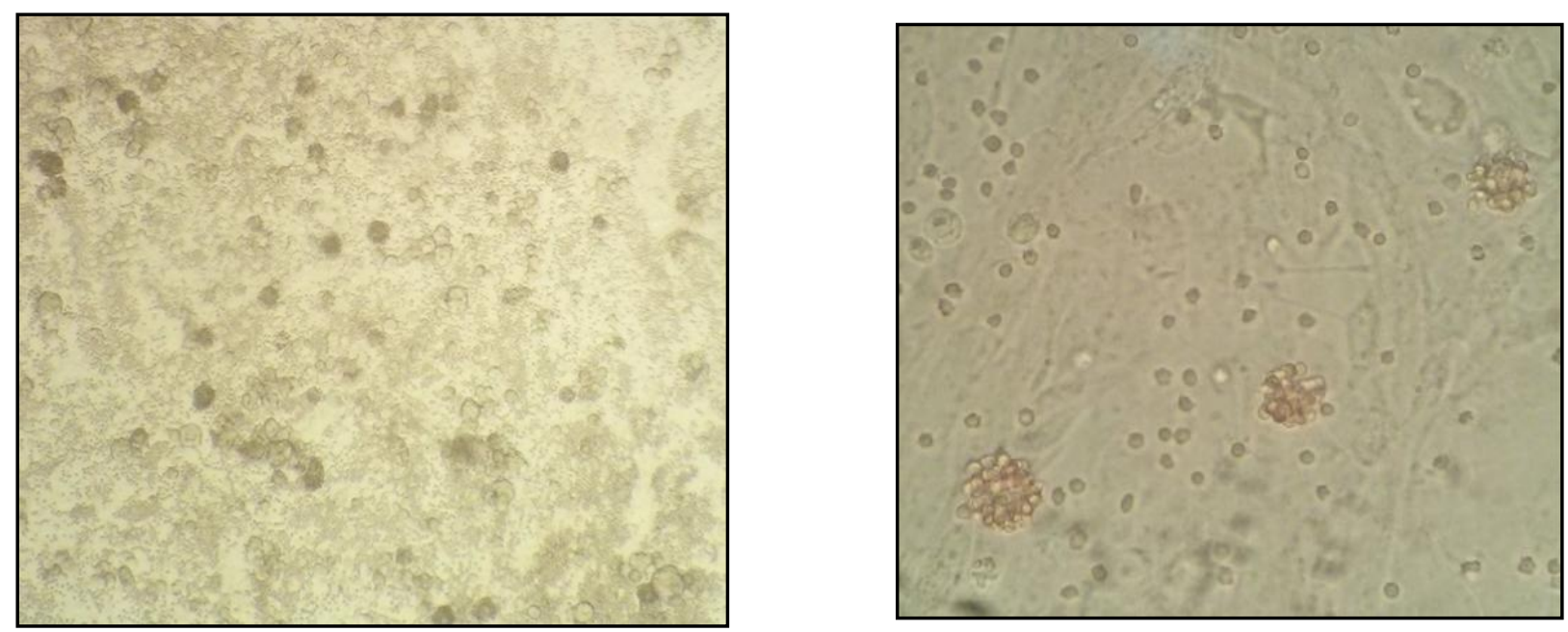

FIGURE 2 - CPE AND HEMADSORPTION BY ASF VIRUS ODINTSOVO 02/14 ISOLATE IN PK PRIMARY CELL CULTURE (left - magnification 200x, right - magnification 400x). 
Five serial passages in PK primary cell culture were performed; the passage duration was 7 days (results are given in Table 2).

TABLE 2

STUDY OF ODINTSOVO 02/14 ISOLATE REPRODUCTION IN PK PRIMARY CELL CULTURE

\begin{tabular}{|c|c|c|c|c|}
\hline \multirow{2}{*}{ Isolate } & Passage & $\begin{array}{c}\text { Number of RBC attached } \\
\text { to the infected cell }\end{array}$ & $\begin{array}{c}\text { Virus accumulation } \\
\text { titer } \\
\left(\mathbf{l g} \mathbf{H A D}_{\mathbf{5 0}} / \mathbf{c m}^{\mathbf{3}}\right)\end{array}$ & $\begin{array}{c}\text { Virus } \\
\text { accumulation } \\
\text { time (days) }\end{array}$ \\
\hline \multirow{4}{*}{ Odintsovo 02/14 } & 1 & $<50$ & $5,08 \pm 0,45$ & 9 \\
\cline { 2 - 5 } & 2 & $<50$ & $5,46 \pm 0,31$ & $8-9$ \\
\cline { 2 - 5 } & 3 & $10-30$ & $6,09 \pm 0,41$ & $6-7$ \\
\cline { 2 - 5 } & 4 & $10-30$ & $6,36 \pm 0,12$ & 6 \\
\hline
\end{tabular}

During the experiment (Table 2) Odintsovo 02/14 isolate was found to be able to reproduce in PK primary cell culture. Replication began without prior adaptation, and hemadsorption was detected at the first passage. By the fifth passage the accumulation time decreased from 9 to 6 days, while the accumulation titer increased from 5.08 to $6,65 \lg \mathrm{HAD}_{50} / \mathrm{cm}^{3}$.

\subsection{Biological properties}

\subsubsection{First experiment}

First group of pigs (5000 HAD/IM) showed hyperthermia with maximum temperature level $41,5^{\circ} \mathrm{C}$ at 6 days post-infection (d.p.i.). Animals died on13 d.p.i.

Within the second groud (5000 HAD/IN) only one pig showed hyperthermia on 6 d.p.i and died on 14 d.p.i. The other pig from this group developed a stable hyperthermia with maximum temperature $41,8^{\circ} \mathrm{C}$ only on 16 d.p.i., and died on 22 d.p.i.

Within the third group of two pigs (50 HAD/IN) the onset of hyperthermia was observed on 24-25 d.p.i. These animals were slaughtered on 30-31 d.p.i. Maximum temperature reached $41,8^{\circ} \mathrm{C}$.

Regarding direct-contact pigs, the maximum temperature reached was $41,6^{\circ} \mathrm{C}$. Clinical signs were observed at 26 d.p.i., and death of animals occurred at 32-33 d.p.i. (Figure 3).

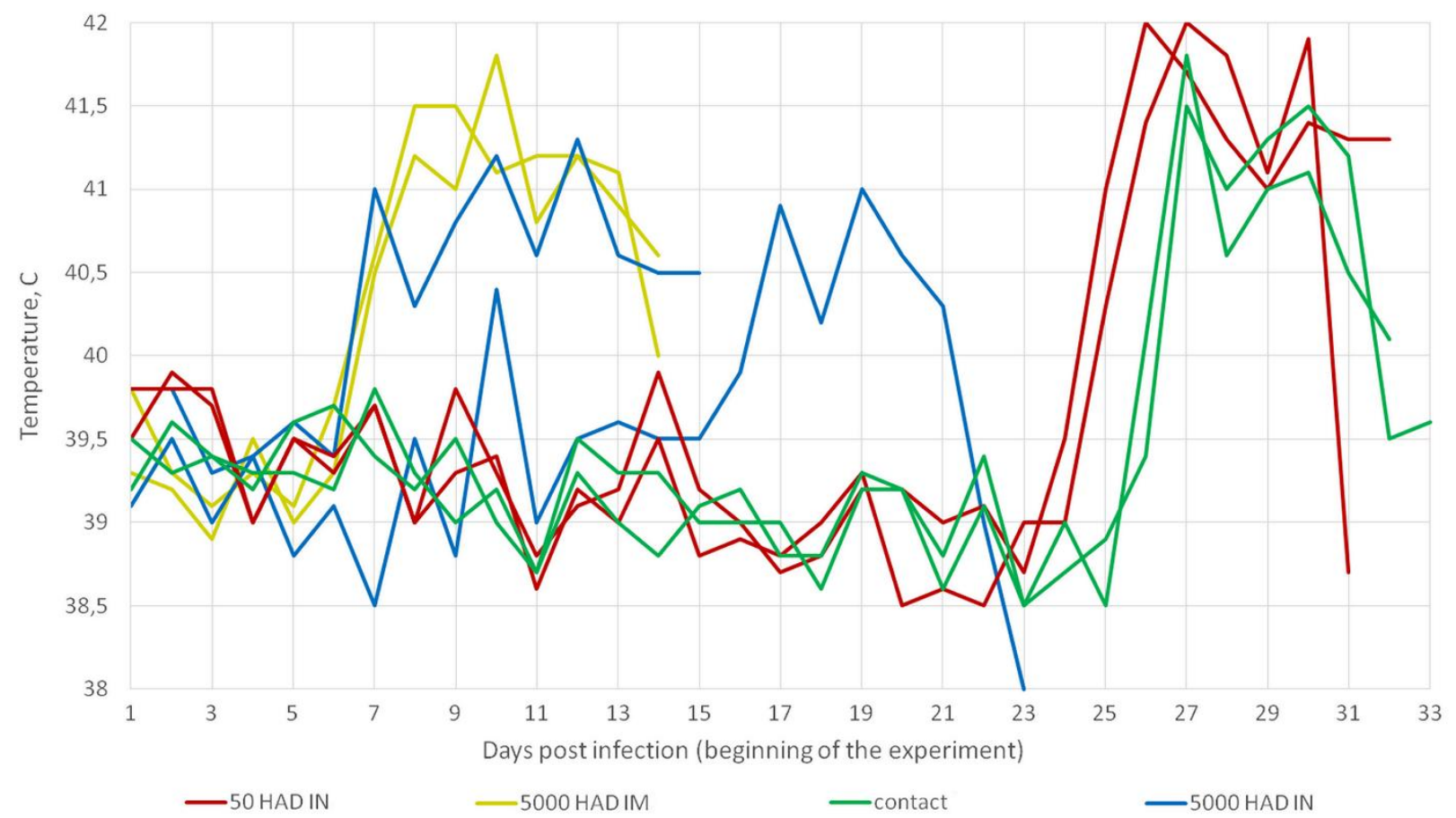

\section{FIGURE 3 - TEMPERATURE GRAPH OF PIGS INFECTED WITH ASFV ODINTSOVO 02/14 ISOLATE, (FIRST EXPERIMENT).}


At autopsy, all dead animals demonstrated changes, specific to ASF: splenomegaly, hyperplasia and hyperemia of the regional lymph nodes, hemorrhages under the renal capsule, and in the bladder lining. These changes were less expressed in animals that died in the early stages (14 d.p.i.), and were more expressed in animals that died during the later stages (31-33 d.p.i.).

Blood and internal organs samples of all animals were investigated by HAD reaction (Table 3), DIF and PCR, for the presence of ASF virus, its antigens and genome, respectively.

\section{TABLE 3}

VIREMIA LEVEL ANALYSIS IN PIGS, INFECTED BY ASF VIRUS ODINTSOVO 02/14.

\begin{tabular}{|c|c|c|c|c|c|c|c|c|c|c|c|c|c|c|c|c|}
\hline \multirow{2}{*}{ Group } & \multirow{2}{*}{$\begin{array}{c}\text { Dose } \\
\left(\lg \mathbf{H A D}_{50} \mathbf{c m}^{3}\right)^{*}\end{array}$} & \multicolumn{15}{|c|}{ Days post infection } \\
\hline & & 3 & 5 & 7 & 9 & 11 & 13 & 15 & 17 & 19 & 21 & 23 & 25 & 27 & 29 & 31 \\
\hline \multirow{2}{*}{1} & \multirow{2}{*}{5000 HAD IN } & $\begin{array}{l}1,77 \pm \\
0,23\end{array}$ & $\begin{array}{c}2,51 \pm \\
0,32\end{array}$ & $\begin{array}{c}5,07 \pm \\
0,11\end{array}$ & $\begin{array}{c}6,51 \pm \\
0,11\end{array}$ & $\begin{array}{c}7,45 \pm \\
0,18\end{array}$ & $\begin{array}{c}6,08 \pm \\
0,17\end{array}$ & $\begin{array}{c}4,53 \pm \\
0,33\end{array}$ & $\begin{array}{c}7,21 \pm \\
0,45\end{array}$ & $\begin{array}{c}6,46 \pm \\
0,35\end{array}$ & $\begin{array}{c}5,87 \pm \\
0,13\end{array}$ & & & & & \\
\hline & & $\begin{array}{c}1,68 \pm \\
0,12\end{array}$ & $\begin{array}{c}3,53 \pm \\
0,13\end{array}$ & $\begin{array}{c}6,54 \pm \\
0,19\end{array}$ & $\begin{array}{c}7,03 \pm \\
0,11\end{array}$ & $\begin{array}{c}7,66 \pm \\
0,14\end{array}$ & $\begin{array}{c}7,05 \pm \\
0,22\end{array}$ & & & & & & & & & \\
\hline \multirow{2}{*}{2} & \multirow{2}{*}{50 HAD IN } & - & - & - & - & - & - & $<1,0$ & $\begin{array}{c}2,34 \pm \\
0,32\end{array}$ & $\begin{array}{c}3,43 \pm \\
0,19\end{array}$ & $\begin{array}{c}5,07 \pm \\
0,12\end{array}$ & $\begin{array}{c}6,08 \pm \\
0,27\end{array}$ & $\begin{array}{c}6,66 \pm \\
0,13\end{array}$ & $\begin{array}{c}7,45 \pm \\
0,18\end{array}$ & $\begin{array}{c}6,74 \pm \\
0,29\end{array}$ & $\begin{array}{c}6,07 \pm \\
0,12\end{array}$ \\
\hline & & - & - & - & - & - & - & $\begin{array}{l}1,87 \pm \\
0,13\end{array}$ & $\begin{array}{c}2,54 \pm \\
0,11\end{array}$ & $\begin{array}{c}3,53 \pm \\
0,11\end{array}$ & $\begin{array}{c}5,56 \pm \\
0,15\end{array}$ & $\begin{array}{c}7,05 \pm \\
0,22\end{array}$ & $\begin{array}{c}4,86 \pm \\
0,24\end{array}$ & $\begin{array}{c}7,66 \pm \\
0,14\end{array}$ & $\begin{array}{c}6,16 \pm \\
0,40\end{array}$ & \\
\hline \multirow{2}{*}{3} & \multirow{2}{*}{5000 HAD IM } & $<1,0$ & $\begin{array}{c}2,68 \pm \\
0,14\end{array}$ & $\begin{array}{c}4,37 \pm \\
0,21\end{array}$ & $\begin{array}{c}6,66 \pm \\
0,13\end{array}$ & $\begin{array}{c}7,02 \pm \\
0,51\end{array}$ & $\begin{array}{c}6,45 \pm \\
0,18\end{array}$ & & & & & & & & & \\
\hline & & $<1,0$ & $\begin{array}{c}2,56 \pm \\
0,07\end{array}$ & $\begin{array}{c}4,29 \pm \\
0,61\end{array}$ & $\begin{array}{c}6,57 \pm \\
0,18\end{array}$ & $\begin{array}{c}7,56 \pm \\
0,41\end{array}$ & $\begin{array}{c}6,66 \pm \\
0,14\end{array}$ & & & & & & & & & \\
\hline \multirow{2}{*}{4} & \multirow{2}{*}{ Contact } & & & - & - & - & - & - & - & - & $\begin{array}{l}1,77 \pm \\
0,23\end{array}$ & $\begin{array}{c}3,53 \pm \\
0,13\end{array}$ & $\begin{array}{c}5,43 \pm \\
0,17\end{array}$ & $\begin{array}{c}6,96 \pm \\
0,17\end{array}$ & $\begin{array}{c}7,45 \pm \\
0,18\end{array}$ & $\begin{array}{c}6,07 \pm \\
0,12\end{array}$ \\
\hline & & & & - & - & - & - & - & - & - & $\begin{array}{c}1,68 \pm \\
0,11\end{array}$ & $\begin{array}{c}2,28 \pm \\
0,14\end{array}$ & $\begin{array}{c}3,53 \pm \\
0,11\end{array}$ & $\begin{array}{c}6,04 \pm \\
0,42\end{array}$ & $\begin{array}{c}7,66 \pm \\
0,14\end{array}$ & $\begin{array}{c}5,07 \pm \\
0,11\end{array}$ \\
\hline
\end{tabular}

Therefore, the mortality rate for pigs in a first experiment was $100 \%$.

\subsubsection{Second experiment}

In a second experimental challenge we used Odintsovo 02/14 isolate (3rd passage in PBM cell culture) to test the structure of the viral population and to determine the biological properties of this isolate. Additionally, we reduced the infection dose and used 14 animals.

Since we determined differences in the duration of the disease, it was necessary to find out correlations between changes of the biological properties and genome of Odintsovo 02/14 isolate.

In the second experiment 4 out of 5 pigs infected with a 50 HAD dose died between 10-16 d.p.i.;. 4 out of 5 pigs infected with 10 HAD dose died between 10-18 d.p.i.. There were surviving pigs in every group. Pig №3 infected with a 10 HAD dose showed no reaction to the introduction of the virus. Pig №8 which was infected by 50 HAD dose expressed single temperature peak at 25 d.p.i. (Figure 4). 


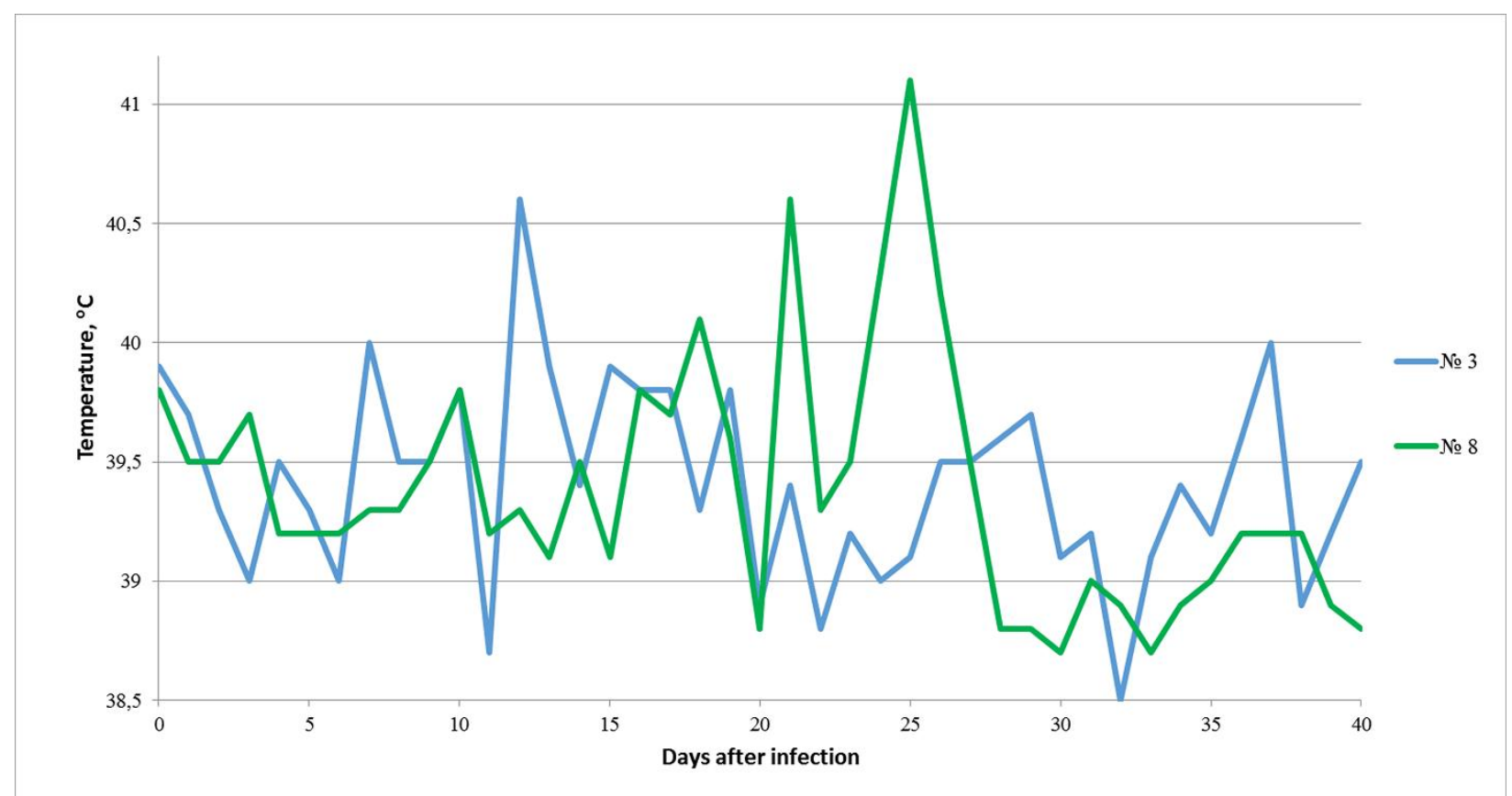

\section{FIGURE 4 - TEMPERATURE GRAPH OF SURVIVING PIGS, INFECTED WITH ASFV ODINTSOVO 02/14 ISOLATE FROM $3^{\text {RD }}$ PASSAGE IN PBM CELL (SECOND EXPERIMENT).}

We did not register any other specific reactions to ASFV injection in pigs for 40 d.p.i. (observation period).

Analysis of the antibodies levels in surviving pigs serum showed that in pig №3 antibodies were detected at 9 d.p.i., while for pig №8 antibodies were detected at 12 d.p.i. (Table 4).

\subsubsection{Third experiment}

At 40 d.p.i. we challenged both surviving pigs by 1000 HAD dose of high virulent ASF virus Boguchary 06/13 isolate, described previously [25]. At the observation time (90 days) we did not registered any symptoms of ASF in these pigs. Therefore, these pigs acquired protective immunity against ASF.

\subsection{Genome analysis}

We prepared three series of ASFV Odintsovo 02/14 - containing culture fluid with a total volume of more than 7 liters for virus purification and DNA isolation (Table 4).

\section{TABLE 4}

VIRUS PURIFICATION AND ASF VIRUS DNA EXTRACTION RESULTS

\begin{tabular}{|c|c|c|c|c|}
\hline № & Volume $\left(\mathrm{cm}^{3}\right)$ & $\begin{array}{c}\text { Virus titer } \\
\left(\lg \mathrm{HAD}_{50} / \mathrm{cm}^{3}\right)\end{array}$ & $\begin{array}{c}\text { Purity of the isolated } \\
\text { DNA } \\
\left(\mathrm{A}_{260} / \mathbf{A}_{280}\right)\end{array}$ & $\begin{array}{c}\text { Resulting DNA } \\
\text { concentration }\left(\mu \mathrm{g} / \mathrm{cm}^{3}\right)\end{array}$ \\
\hline 1 & 2500 & 6,02 & $\sim 2,03$ & 64,2 \\
\hline 2 & 2400 & 5,67 & $\sim 1,89$ & 72,1 \\
\hline 3 & 2300 & 4,75 & $\sim 1,93$ & 39,6 \\
\hline
\end{tabular}

As seen from the Table 4, we obtained unfragmented genomic ASF virus DNA. Sample 1 had optimal indicator of purity and concentration, therefore it was chosen for further pyrosequencing.

\subsection{Comparative analysis.}

The genome of Georgia 2007/01 isolate is 189 344bp long (GenBank accession no.: FR682468.) However, sequence analysis of Odintsovo 02/14 isolate revealed a genome of 189 333bp long (accession no. KM262844). The majority of differences were located in the left (LVR) and right variable (RVR) regions of the genome, with $45.8 \%$ of them localized in the LVR.

The comparative analysis indicated that the genome of ASF virus Odintsovo 02/14 isolate has 22 mononucleotide insertions, 3 polynucleotide insertions, including a direct tandem repeat, 35 mononucleotide and 5 polynucleotide deletions, also 7 
substitutions. In comparison to Georgia 2007/01 genome (189 344 nucleotides), these changes in the Odintsovo 02/14 genome constitute to $\sim 0.038 \%$ of its total length (Table 5 ).

The first key difference was the presence of the tandem repeat sequence GGAATATATA in the intergenic region between genes I73R and I329L of Odintsovo 02/14 isolate, which was absent in Georgia 2007/1 genome.

TABLE 5

CHANGED GENES OF ODINTSOVO 02/14 ISOLATE

\begin{tabular}{|c|c|c|c|c|}
\hline ORF & Location & Gene & Function & Change \\
\hline 4 & 4114 & L83L & unknown (BA71V-L83L) & + T \\
\hline 7 & 5670 & ASFV_G_ACD_00070 & ASFV-Georgia_Final_2-007 & + A \\
\hline 8 & 6095 & MGF_110-1L & 110 Multigene & C/T \\
\hline 12 & 7940 & ASFV_G_ACD_00120 & ASFV-Georgia_final-012 & + A \\
\hline 29 & 16663 & ASFV_G_ACD_00290 & ASFV-Georgia_final-029 & - GG \\
\hline 54 & 43599 & MGF_505-9R & 505 Multigene & A/G \\
\hline 117 & 124803 & CP204L & p30 phosphoprotein. Involved in & + virus entry. \\
\hline 124 & 133521 & NP419L & DNA ligase & T/C \\
\hline 147 & 161252 & QP383R & NifS like protein (BA71V-QP383R) & - A \\
\hline $162-163$ & 172407 & I243L-I73R & New intergene region & + GAATATATAG \\
\hline 168 & 175376 & I196L & unknown (BA71V-I196L) & T/C \\
\hline
\end{tabular}

According to the analysis of changes and summarizing the data presented in Table 5, we can conclude, that the genomic structure of ASF virus Odintsovo 02/14 differs from Georgia 2007/1 isolate. Changes include: genes encoding structural and functional proteins of the virus, replacements of genes in multigene families (MGF_110-1L, MGF_505-9R) which are responsible for virulence [15]. Mapping of the changes in ASFV to its functional map indicated that some of the changes occurred in genes of multigene families, pA403, pKP360 and pL356L, which according to L. Dixon can lead to reduction of virulence of the ASF virus.

\section{DISCUSSION}

Our study has been conducted at the Reference Laboratory for ASF (FGBI "ARRIAH"), attempting to resolve the intragenotypic relationships of ASF viruses that have been causing outbreaks in Russian Federation over a period of 8 years, and to detect epidemiological links that may exist between outbreaks from different regions. Nevertheless, the low levels of intragenotype diversity among field isolates collected for the past three years make it harder to clarify the relation within genotype.

Belyanin A.S. et al noted that, for Russian Federation ASFV isolates 2007-2012 the incubation period was 4.0 (3.0-5.0) days and the infectious period (duration of illness) - 6.5 (5.0-8.0) days on experimental swine. There were edema and multiple hemorrhages in all organs of infected animals with viremia level reaching HAD $6,5-7,5 \mathrm{lg}_{50} / \mathrm{cm}^{3}$ with $100 \%$ mortality rate $[3]$.

We analyzed the influence of infection routes on illness duration and death onset on pigs challenged in the same dose (5000 HAD). The IN challenge led to prolongation of manifestation of the disease for 2-10 days and postponing of pigs death for 19 days comparing to IM infection.

The influence of the infecting dose on development of the disease was noted in our earlier studies. In this study (Experiment 1) clinical signs in pigs infected with 5000 HAD occurred 8-18 days earlier compared to pigs infected with 50 HAD. Effects of dose and infection route in terms of the onset of hyperthermia and death were confirmed in similar research in the study of the biological properties of other ASF virus samples, isolated in Russian Federation.

We noticed an increase in the duration of the incubation period. In groups 1 and 2, the incubation period for the two pigs infected IM and one infected IN with 5000 HAD lasted for 6 days, which converges with the data obtained from previously described isolates. However, for one pig infected IN with 5000 HAD the incubation period lasted for 16 d.p.i.. 
In group 3 the incubation period for two pigs infected IN with 50 HAD lasted 24-25 d.p.i.. The longest incubation period ( 28 days) was observed in a contact group. The average life span post infection for contact animals was $\sim 7$ days as therefore did not differ from other groups.

Thus, the duration of the incubation period was significantly longer than previously recorded for Russian isolates 2007-2011 (2-4 d.p.i.) $[3,4,7]$.

S. Blum et al. conducted a study using high, moderate and low infection doses of ASFV Caucasian strains to assess the risk of development of chronic disease and virus infection. They showed that low dose infection may lead to prolonged incubation periods and clinical courses, and that $1000 \mathrm{HAD}$ are not sufficient to produce disease in healthy wild boars [6, 7].

Differences in the incubating period span for pigs, challenged with $50 \mathrm{HAD}$ dose could be due to an individual differences in the immune response of pigs or heterogeneous composition of Odintsovo 02/14 isolate population.

To analyze population structure of Odintsovo 02/14 isolate we used two samples: one from the spleen of a wild boar, and second was passed no more than 3 times in PBM cells, as according to P.W. Krug no considerable changes in the viral genome can occur in these circumstances if the virus population is homogeneous [20]. Otherwise, if it is heterogeneous, reproduction in the culture cells can change the structure of the population. The fact that 2 pigs withstanded the challenge with 3rd passage of Odintsovo 02/14 isolate in PMB cell culture without any simptoms may indicate the presence of an avirulent component in the viral population.

Mapping of the changes in ASFV to its functional map by L.K. Dixon et al., indicated changes in the genes of a multigene family MGF_505, as well as genes encoding CD2v protein and both DNApol, and Guanylyl transferase enzymes, which may affect the rate of the virus replication, and therefore virulence [14].

In this study, the detection of gene(s) responsible for changes in the biological properties of Odintsovo 02/14 isolate was not possible. However it allowed us to make assumptions about the causes of increased incubation period through the analysis of the correlation between biological properties and alterations in ASFV genome.

In the genome of Odintsovo 02/14 we found 22 mononucleotide insertions, 3 polynucleotide insertions, including a direct tandem repeat GAATATATAG, 35 mononucleotide and 5 polynucleotide deletions, and 7 substitutions.

The 454 GS Junior sequencer (Roche) may produce mistakes sequencing homopolymer sequences longer than 6 nucleotides; it permits 0.38 errors per 100 bases. In general, those mistakes are mononucleotide deletions which can be formed even at a high depth of coverage [22]. Analysis of the Odintsovo 02/14 nucleotide sequence allowed us to identify genes containing incontestable changes $-37.5 \%$ of the variation of the total amount.

These included changes (T/C) in NP419L gene, encoding an ATP-dependent viral DNA-ligase which is part of the viral DNA-repair enzymes complex. It is characterized by extremely high tolerance for errors at the crosslinking chains reparation [34].

We also detected changes in the nucleotide sequences of ASFV_G_ACD_00070, I196L and M448R genes, those which have an unknown function yet, and genes of multigene families MGF_360-1L, MGF_360-2L, MGF_110-1L, MGF_505-9R. It is possible that these changes have led to an increased incubation period in pigs infected with Odintsovo 02/14.

Changes in the intergenic areas of the genome may also have an impact on virulence, for example by affecting promoter or other regulatory sequences [26]. We found out that the genome of ASFVOdintsovo 02/14 isolate has a tandem repeat GGAATATATA in the nucleotide sequence of the intergenic region I73R/I329L. Its presence according to Gallardo C. et al., was not identified in Russian isolates between 2007 and 2010. This tandem repeat was noted by the authors only in European isolates 2013-2014 years and in the genome of Ukrainian isolate in 2012 [17]

\section{CONCLUSION}

Cultural properties of Odintsovo 02/14 isolates are significantly different amongst other Russian isolates 2007-2014. It manifests a decreased amount of RBC's, attached to an infected cell, which according to L.Dixon is related to attenuation of the virus.

Mortality in infected animals reached $100 \%$ for the samples of spleen suspension and $85.7 \%$ for the 3rd PBM cells passage samples, when we used $50 \mathrm{HAD}$ dose for the challenge, which may indicate the heterogeneity of the viral population of this isolate and presence of viral variants with different pathogenicity. 
A comparative analysis of the nucleotide sequences of Odintsovo 02/14 and Georgia 2007/1 ASFV isolates identified differences in genes responsible for virus attachment, cell penetration and host immune system evasion genes. Changes were found in nucleotide sequences of genes I196L, NP419L, ASFV_G_ACD_00070, M448R, MGF_360-1L, MGF_360-2L, MGF_110-1L, MGF_505-9R and GGAATATATA tandem repeat sequence in the intergenic region I73R/I329L, which is absent in the ASF isolates collected before 2012.

The analysis highlighted group of genes of Odintsovo 02/14 isolate, where changes are undoubted (37.5\% of the total variations, where $23.6 \%$ are mononucleotide deletions/insertions). These include nucleotide replacement T/C in a NP419L gene encoding the ATP-dependent viral DNA-ligase complex, included in the viral reparation. It is characterized by an extremely high tolerance for errors in the presence of crosslinking chains by crosslinking nick breaks [15].

Due to variations in a number of tandem repeats in a nucleotide sequence of the ASFV I196L gene it was used for phylogenetic analysis of ASFV isolates [15]. These changes may have led to an increased incubation period in pigs infected with Odintsovo 02/14. The detected changes in the gene sequences require further study.

\section{REFERENCES}

[1] Afonso, C.L., Piccone, M.E., Zaffuto K.M., Neilan J.; Kutish G.F., Lu Z.; Balinsky C.A., Gibb T.R., Bean, T.J., Zsak, L.; Rock D.L. 2004. African swine fever virus multigene family 360 and 530 genes affect host interferon response // Journal Of Virology. 78(4): 1858-1864.

[2] Arias M., Sanchez-Vizcaino J.M., Morilla A. [et al.] 2002. African swine fever eradication: the Spanish model// Trends in Emerging Viral Infections of Swine / ed. A. Morilla, K. Jin, J. Zimmerman. -1st ed. - Ames, Iowa, USA: 133-139.

[3] Balyshev V.M., Kurinnov V.V., Tsybanov S.Zh., Kalantaenko Yu.F., Kolbasov D.V., Pronin V.V., Korneva G.V. 2010. Biological properties of African swine fever virus isolated in the Russian Federation.// Veterinariya. 7: 25-27.

[4] Belyanin S.A., Vasilev A.P., Kolbasov D.V., Tsybanov S.Zh., Balyshev V.M., Kurinnov V.V., Chernykh O.Yu. 2011. Virulence of African swine fever isolates // Veterinary of Cuban. 5: 9-11.

[5] Black, D.N.; Brown, F. 1976. Purification and physicochemical characteristics of african swine fever virus.// Journal Of General Virology. 32(3): 509-518.

[6] Blome S., Gabriel C., Beer M. 2013. Pathogenesis of African swine fever in domestic pigs and European wild boar.// Virus Research 173: $122-130$.

[7] Blome, S., Gabriel, C., Dietze, K., Breithaupt, A., Beer, M., 2012. High virulence of African swine fever virus caucasus isolate in European wild boars of all ages.// Emerging Infectious Diseases 18 (4): 708.

[8] Box, G.E.P.; Hunter, W.G.; Hunter, J.S. 2005.Statistics for Experimenters: Design, innovation and discovery. (eds). Wiley. 2nd edition. $664 \mathrm{p}$.

[9] Chapman D.A.G., Darby A.C., Da Silva M., Upton C., Radford A.D.; Dixon L.K. 2011. Genomic analysis of highly virulent Georgia 2007/1 isolate of African swine fever virus.// Emerging Infectious Diseases. 17(4): 599-605.

[10] Chapman, D.A.G.; Tcherepanov, V.; Upton, C.; Dixon, L.K. 2008. Comparison of the genome sequences of non-pathogenic and pathogenic African swine fever virus isolates. Journal Of General Virology. 89(2): 397-408.

[11] de León P., Bustos M. J., Carrascosa A.L. 2012. Laboratory methods to study African swine fever virus.// Virus Research; 10: 173(1) DOI: 10.1016/j.virusres.2012.09.013

[12] de Villiersa, E.P.; Gallardo, C.; Arias, M.; da Silva, M.; Upton, C.; Martin, R; Bishop, R.P. 2010. Phylogenomic analysis of 11 complete African swine fever virus genome sequences.// Journal Of Virology. 400(1): 128-136.

[13] Dixon, L. K.; Costa, J. V.; Escribano, J. M.; Rock, D.L.; Vinuela, E.; Wilkinson P.J. 2000. Family Asfarviridae, p. 159-165. In M. H. V. van Regenmortel, C. M. Fauquet, D. H. L. Bishop, E. B. Carstens, M. K. Estes, S. M. Lemon, J. Maniloff, M. A. Mayo, D. J. McGeoch, C. R. Pringle, and R. B. Wickner (ed.)// Virus taxonomy: seventh report of the International Committee on Taxonomy of Viruses. Academic Press, San Diego, Calif.

[14] Dixon, L.K.; Abrams, C.C.; Bowick G.; Goatley, L.C.; Kay-Jackson, P.C.; Chapman, D.A.G.; Liverani, E.; Nix, R.; Silk, R.; Zhang, F. 2014. African swine fever virus proteins involved in evading host defence systems. // Veterinary Immunology and Immunopathology. 100(3-4): 117-134.

[15] Dixon, L.K.; Chapman, D.A.G.; Netherton, C.L.; Upton C. 2013. African swine fever virus replication and genomics.// Virus Research. 173(1) 3-14.

[16] Enjuanes L, Carrascosa AL, Viñuela E. Isolation and properties of the DNA of African swine fever (ASF) virus.// J Gen Virol.1976 Sep;32(3):479-492.

[17] Gallardo C. et al. 2014. Genetic Variation among African Swine Fever Genotype II Viruses, Eastern and Central Europe. //Emerging Infectious Diseases. 9: 1544-1547.

[18] Isolation of african swine fever virus (ASFV) in porcine macrophages and haemoadsortion test / Madrid, Spain: $2014 .-6$ p.

[19] Kleiboeker S.B.; Kutish G.F.; Neilan J.G.; Lu Z., Zsak L., Rock D.L. 1998. A conserved African swine fever virus right variable region gene, I1 1L, is non-essential for growth in vitro and virulence in domestic swine.// Journal Of General Virology. 79(5): 11891195. 
[20] Krug [et al.] P.W. The progressive adaptation of a Georgian isolate of African swine fever virus to Vero cells leads to a gradual attenuation of virulence in swine corresponding to major modifications of the viral genome // Journal of Virology. - 2015. - Vol. 89, № 4. - P. 2324-2332.

[21] Li, H.; Durbin, R. 2010. Fast and accurate long-read alignment with Burrows-Wheeler transform.// Bioinformatics. $26: 589-595$.

[22] Loman N. J., Misra R.V., Dallman T.J. (et al.) 2012. Performance comparison of benchtop high-throughput sequencing platforms.// J. Nature Biotehcnology. 30(5): 434-462.

[23] Malmquist W.A., Hay D. 1960. Hemadsorption and cytopathic effect produced by ASFV in swine bone marrow and buffy coat cultures.// Am. J. Vet. Res.; 21:104-108.

[24] Metzker M.L. 2010. Sequencing technologies - the next generation.// Nature Reviews Genetics. 11: 31-46.

[25] N.N. Vlasova, A. A. Varentsova, I. V. Shevchenko, I. Yu. Zhukov, S. G. Remyga, V. L. Gavrilova, O. S. Puzankova, A. A. Shevtsov, N. G. ZinyakovK. N. Gruzdev. Comparative Analysis of Clinical and Biological Characteristics of African Swine Fever Virus Isolates from 2013 Year Russian Federation // British Microbiology Research Journal, Vol.: 5, Issue.: 3 P. 203-215

[26] Portugal R., Coelho J., Hoper D., Little N. S., Smithson C., Upton C., Martins C., Leitao A. and Keil G. M. Related strains of African swine fever virus with different virulence: genome comparison and analysis// Journal of General Virology (2015), 96, pp.408-419, DOI 10.1099/vir.0.070508-0

[27] Sogo, J.M., Almendral, J.M., Talavera A., Vinuela E. 1984. Terminal and internal inverted repetitions in african swine fever virus DNA.// Journal Of Virology. 133: 271-275.

[28] STATGRAPHICS®Centurion XV User Manual. [Electronic resource] - Access mode. Available: http://gendocs.ru/v31715/программа___statgraphics_centurion_xv

[29] Genetic identification and nucleotide sequence of the DNA polymerase gene of African swine fever virus / A. Martins [et al.] // Nucleic Acids Research. - 1994. - Vol. 22, № 2. - P. 208-213.

[30] Torresi C. Application of Next-Generation Sequencing (NGS) technologies to the African Swine Fever Virus (ASFV) // Short Term Mission Report- www.sidilv.org/.../76-report-borse-di-studio-cla...

[31] Yanez, R.J.; Rodriguez, J.M.; Nogal, M.L.; Yuste, L.; Enriquez, C.; Rodriguez, J.F.; Vinuela, E. 1995. Analysis of the Complete Nucleotide Seqence of African Swine Fever Virus.// Journal Of Virology. 208(1): 249-278.

[32] Zhou X., Ren L., Li Y., Zhang M., Yu Y., Yu J. 2010. The next-generation sequencing technology: A technology review and future perspective.// Science China Life Sciences. 53: 44-57.

[33] Genotyping field strains of African swine fever virus by partial p72 gene characterisation / A. Bastos [et al.] // Archives of Virology. 2003. - Vol. 148, № 4. - P. 693-706.

[34] Lamarche, B.J. ASFV DNA polymerase $X$ is extremely error-prone under diverse assay conditions and within multiple DNA sequence contexts / B.J. Lamarche, S. Kumar, M.D. Tsai // Biochemistry. - 2006. - Vol. 45, № 49. - P. 14826-14833. 